\title{
A Th1/Th2-associated chemokine imbalance during infancy in children developing eczema, wheeze and sensitization
}

Thomas Abrahamsson, Martina Sandberg, Anna Forsberg, B Bjorksten and Maria Jenmalm

\section{Linköping University Post Print}

N.B.: When citing this work, cite the original article.

This is the authors' version of the following article:

Thomas Abrahamsson, Martina Sandberg, Anna Forsberg, B Bjorksten and Maria Jenmalm, A Th1/Th2-associated chemokine imbalance during infancy in children developing eczema, wheeze and sensitization, 2011, Clinical and Experimental Allergy, (41), 12, 1729-1739.

which has been published in final form at:

http://dx.doi.org/10.1111/j.1365-2222.2011.03827.x

Copyright: Blackwell Publishing http://www.blackwellpublishing.com/

Postprint available at: Linköping University Electronic Press http://urn.kb.se/resolve?urn=urn:nbn:se:liu:diva-73095 


\title{
A Th1/Th2-associated chemokine imbalance during infancy in children developing eczema, wheeze and sensitization
}

\author{
Thomas R Abrahamsson, $\mathrm{MD}, \mathbf{P h D}^{1}$ \\ Martina Abelius, MSc ${ }^{1,2}$ \\ Anna Forsberg MSc ${ }^{1,2}$ \\ Bengt Björkstén, MD, PhD $^{3}$ \\ Maria C Jenmalm, $\mathbf{P h D}^{1,2}$
}

1. Department of Clinical and Experimental Medicine, Division of Pediatrics,

Linköping University, Sweden

2. Department of Clinical and Experimental Medicine, Unit of Autoimmunity and Immune Regulation, Division of Clinical Immunology, Linköping University, Sweden

3. Institute of Environmental Medicine, Karolinska Institutet, Stockholm, Sweden

Correspondence to: Thomas Abrahamsson

Division of Paediatrics

Linköping University Hospital

SE-581 85 Linköping,Sweden

Phone: +46-(10)-1030000

Fax: +46-(13)-148265.

E-mail: thomas.abrahamsson@lio.se 
Abrahamsson 


\section{Abstract}

Background: Analyses of circulating chemokines offer novel tools to investigate the Th1/Th2 imbalance in allergic disease in vivo.

Objective: To relate circulating Th1- and Th2-associated chemokines in infancy to allergic disease, sensitization and probiotic supplementation.

Methods: Circulating levels of Th1-associated CXC-chemokine ligand (CXCL)9, CXCL10 and CXCL11 and Th2-associated CC-chemokine ligand (CCL)17 and CCL22 were assessed with Luminex and CCL18 with ELISA at birth $(n=109), 6(n=104), 12(n=116)$ and 24 months $(\mathrm{n}=123)$ in 161 infants completing a double-blind placebo-controlled allergy prevention trial with Lactobacillus reuteri during the last month of gestation and through the first year of life. The infants were followed regarding development of allergic disease and sensitization until two years of age.

Results: The Th2-associated chemokines CCL17 and CCL22 were as highest at birth and then decreased, whereas CCL18 and the Th1-associated chemokines increased with age. High Th2-associated chemokine levels were observed in children developing allergic disease. Sensitization was preceded by elevated levels of the Th2-associated CCL22 and reduced levels of the Th1-associated CXCL11 already at birth. The Th2-associated CCL17 was also elevated at birth in infants developing recurrent wheeze. A high Th2/Th1-ratio (CCL22/CXCL10) at birth associated with both sensitization and eczema development. Presence of $L$. reuteri in stool the first week of life was associated with low CCL17 and CCL22 and high CXCL11 levels at six months of age. High Th1-associated chemokine levels were associated with day-care.

Conclusion and Clinical Relevance: Allergic disease and sensitization in infancy was associated with low circulating Th1- and high Th2-associated chemokine levels already from birth. Circulating chemokines are useful for investigating the Th1/Th2 imbalance in allergic 
Abrahamsson

disease in vivo. Elucidation of the role of chemokines in allergic diseases may lead to future treatments. (ClinicalTrials.gov NCT01285830)

\section{Key words}

Wheeze; eczema; chemokine; day-care; infant; Lactobacillus reuteri; pregnancy; probiotics; sensitization; skin prick test 


\section{Introduction}

Allergy development has been attributed to a delayed maturation of the immune system with a decreased allergen induced interferon- $\gamma($ IFN- $\gamma)$ production at birth [1] and a prolonged postnatal Th2-deviation in childhood [2,3]. Yet, it is still somewhat controversial whether Th2-deviation increases the risk for allergic disease or not. For example, children in developing countries with a strong Th2-deviation, due to chronic parasite infection, do not run an increased risk for allergic disease [4]. Also, both Th1-associated autoimmune diseases, such as Mb Crohn and diabetes mellitus, and allergic disease have increased in affluent countries [5]. Although the increase of allergic disease obviously depends on environmental factors, it has been difficult to link laboratory markers of Th2-devation to such factors in humans in vivo. This might be a methodology issue. Appropriately powered prospective studies from birth are needed, as well as reliable markers in peripheral blood.

Circulating Th1 and Th2 cytokine levels are low and close to detection limit [6]. Chemokines, on the other hand, are easily detected in peripheral blood [6]. They comprise a large protein family responsible for the trafficking of leukocytes to the site of inflammation and the regulation of leukocyte maturation [7]. Their receptors are expressed on the surface of several cell types involved in the allergic inflammation: e.g. CC receptor 4 (CCR4) on eosinophils and Th2 lymphocytes and CXC receptor 3 (CXCR3) on Th1 lymphocytes and natural killer cells [7]. Atopic dermatitis is associated with high circulating levels of the Th2-cytokine induced CCR4 ligands CCL17 and CCL22 [8-10], as well as CCL18 (unknown receptor) [11], in children and adults. Furthermore, increased levels of CCL17, CCL18 and CCL22 in bronchoalveolar lavage (BAL) fluid have been reported in asthmatics $[12,13]$ and after allergen challenge [14]. In contrast, the IFN- $\gamma$ induced CXCR3 ligands CXCL10 and CXCL11 are associated with Th1-like diseases, such as sarcoidosis, tuberculosis [15] and 
Crohn's disease [16]. It is not known, however, whether any of these chemokines are primarily involved in the pathogenesis of allergic diseases or merely are secondary to a general immune deviation.

We have previously reported that $L$. reuteri treatment was associated with a lower incidence of sensitization and IgE-associated disease [17]. This study provided an opportunity to relate circulating Th1- and Th2-associated chemokines to the development of allergic disease, probiotic supplementation and environmental factors in infancy. We hypothesized that high levels of circulating Th1- and low levels of Th2-associated chemokines would be associated with $L$. reuteri supplementation and reduced incidence of sensitization and allergic disease during infancy, and that factors possibly decreasing the risk of allergic disease, e.g. day-care, would relate to elevated Th1- and reduced Th2-associated chemokines, while the chemokine pattern was opposite for factors increasing the risk. 


\section{Methods}

Study design

This was a part of a prospective, double-blind, placebo-controlled, multi-centre trial in South Eastern Sweden comprising 232 families with at least one family member with allergic disease, assessing the potential allergy preventing effect of probiotics [17]. The mothers started taking Lactobacillus reuteri ATCC 55730 (1 x $10^{8}$ CFU, BioGaia AB, Stockholm, Sweden) or placebo four weeks before term and continued to do so daily until delivery. After birth, the baby commenced with the same study product as the mother at 1-3 days of age and continued daily for one year. The infant was followed up another year regarding the development of allergic disease with or without positive skin prick test (SPT) or circulating IgE to food allergens.

As previously described in detail [17], clinical follow-up was done at 1, 3, 6, 12 and 24 and telephone interviews at $2,4,5,8,10$ and 18 months by a research nurse and the final diagnosis by a paediatrician at 24 months of age. A questionnaire was completed on each occasion. In all, 188 infants completed the original study, and 161 of these, where blood samples were available, were included in the present study ( 81 in the treated and 80 in the placebo group). The clinical outcome in these 161 infants is described in Table 1 . The active and placebo group did not differ regarding potential confounders, such as sex, birth order, duration of pregnancy, caesarean delivery, parental smoking, family history of allergic disease, breastfeeding, day-care and infections, except for antibiotics, that were more often prescribed in the active than the placebo group (Table 1). An informed consent was obtained from both parents before inclusion. The Regional Ethics Committee for Human Research at Linköping University approved the study. The study is registered at ClinicalTrials.gov (NCT01285830). 
Table 1. Descriptive data of children completing the study.

\begin{tabular}{|c|c|c|c|}
\hline & $\begin{array}{l}\text { Lactobacillus reuteri } \\
\%(\mathrm{n} / \mathrm{N})\end{array}$ & $\begin{array}{l}\text { Placebo } \\
\%(\mathrm{n} / \mathrm{N})\end{array}$ & p-value* \\
\hline Boys & $57(46 / 81)$ & $46(37 / 80)$ & 0.18 \\
\hline First born & $51(41 / 81)$ & $55(44 / 80)$ & 0.58 \\
\hline Caesarean delivery & $11(9 / 81)$ & $11(9 / 80)$ & 0.98 \\
\hline Parental smoking & $7(6 / 81)$ & $13(10 / 80)$ & 0.28 \\
\hline Furred pets & $16(13 / 81)$ & $10(8 / 80)$ & 0.25 \\
\hline Maternal atopy & $74(60 / 81)$ & $75(60 / 80)$ & 0.89 \\
\hline Paternal atopy & $67(54 / 81)$ & $66(53 / 80)$ & 0.95 \\
\hline \multicolumn{4}{|c|}{ Breastfeeding } \\
\hline \multicolumn{2}{|c|}{3 months, exclusive $68(55 / 81)$} & $59(74 / 80)$ & 0.41 \\
\hline 6 months, partial & $83(67 / 81)$ & $83(66 / 80)$ & 0.97 \\
\hline \multicolumn{4}{|l|}{ Antibiotics } \\
\hline 0-12 months & $38(31 / 81)$ & $23(18 / 80)$ & 0.03 \\
\hline $12-24$ months & $43(35 / 81)$ & $46(37 / 80)$ & 0.70 \\
\hline \multicolumn{4}{|l|}{ Day-care } \\
\hline $0-12$ months & $5(4 / 81)$ & $5(4 / 80)$ & 0.99 \\
\hline $12-24$ months & $80(65 / 81)$ & $86(69 / 80)$ & 0.31 \\
\hline \multicolumn{4}{|c|}{ Allergic manifestations** } \\
\hline Recurrent wheeze & $6(5 / 81)$ & $10(8 / 80)$ & 0.37 \\
\hline Eczema & $36(29 / 81)$ & $34(27 / 80)$ & 0.79 \\
\hline Allergic disease & $44(36 / 81)$ & $44(35 / 80)$ & 0.93 \\
\hline Sensitisation & $35(22 / 63)$ & $43(27 / 63)$ & 0.44 \\
\hline IgE-assoc. disease & $14(9 / 63)$ & $32(20 / 63)$ & 0.02 \\
\hline
\end{tabular}

${ }^{*} X^{2}$ test. ${ }^{* *}$ Cumulative incidence until 2 years of age.

\section{Diagnostic criteria of allergic disease}

Allergic disease included eczema, recurrent wheeze, allergic rhinoconjunctitivis, allergic urticaria and gastrointestinal allergy. Eczema was defined as a pruritic, chronic or chronically relapsing non-infectious dermatitis with typical features and distribution. Wheeze was defined as an episode with obstructive airway symptoms, and recurrent wheeze as $\geq 3$ wheezing episodes, at least once verified by a physician. A diagnosis of allergic rhinoconjunctivitis required watery discharge at least twice in contact with the same allergen and no signs of infection. Urticaria was defined as allergic when appearing at least twice in conjunction with 
a certain food. A diagnosis of gastrointestinal allergy required vomiting, diarrhoea or systemic reaction after ingestion of a potentially allergenic food and a confirmation by challenge, unless there was a clear history of a severe systemic reaction. Allergic urticaria, ARC and gastrointestinal allergy were not analyzed separately since the incidence of these manifestations was low $(2.1 \%, 2.7 \%$ and $2.1 \%$, respectively). Infants were regarded as sensitized if they had at least one positive SPT and/or detectable circulating allergen specific IgE antibodies. Allergic disease was classified as IgE-associated if the symptomatic infant also was sensitized.

\section{Sensitization}

Skin prick tests were done on the volar aspects of the forearm with egg white, fresh skimmed cow milk (lipid concentration $0.5 \%$ ) and standardised cat, birch and timothy extracts (Soluprick®, ALK, Hørsholm, Denmark) at 6, 12 and 24 months of age. Histamine hydrochloride $(10 \mathrm{mg} / \mathrm{ml})$ was used as positive and albumin diluents as negative control. The test was regarded as positive if the mean diameter of the wheal was $\geq 3 \mathrm{~mm}$.

Circulating IgE antibodies to egg white and cow's milk were analysed at 6, 12, and 24 months of age in venous blood (UniCap ${ }^{\circledR}$ Pharmacia CAP System ${ }^{\mathrm{TM}}$, Pharmacia Diagnostics, Uppsala, Sweden). The cut off level was $0.35 \mathrm{kU} / \mathrm{L}$, according to the protocol of the manufacturer. In addition, circulating IgE to a mixture of food allergens, including egg white, cow's milk, cod, wheat, peanut and soy bean, was analyzed at 6, 12 and 24 months of age (UniCap ${ }^{\circledR}$ Pharmacia CAP System ${ }^{\mathrm{TM}}$, fx5, Pharmacia Diagnostics).

\section{Bacteriological analyses}

The bacterial analyses in faecal samples are described in detail elsewhere [18]. Briefly, stool samples were collected from the baby at 5 or 6 days of age, weighted, thawed and diluted in 
saline buffer and plated on modified de Man-Rogosa-Sharpe (MRS) agar with $50 \mathrm{mg} / \mathrm{L}$ Vancomycin and 2\% sodium acetate (MRS-3, Acumedia, Ljusne, Sweden). The plates were incubated anaerobically in anaerobic jars with GasPack Plus (Becton Dickinson, Stockholm, Sweden) at $37^{\circ} \mathrm{C}$ for 48 hours. Lactobacillus reuteri colonies were confirmed by detecting reuterin production after addition of glycerol.

\section{Chemokine analyses in venous blood}

Venous blood were collected from the umbilical cord $(n=109)$ and at $6(n=104), 12(n=116)$ and 24 months $(\mathrm{n}=123)$ and stored in $-20^{\circ} \mathrm{C}$ as heparinized plasma or serum until assessment. The chemokines CXCL9, CXCL10, CXCL11, CCL17 and CCL22 were analyzed with a Luminex assay, modified from [19].

\section{Luminex assay:}

Before commencing the multiplexed assay, monoclonal capture antibodies were covalently coupled to carboxylated microspheres, by the procedure recommended by the manufacturer (Luminex Corporation, Austin, TX, USA). $5 \mu \mathrm{g}$ antibody $/ 10^{6}$ microspheres of monoclonal anti-human CXCL9 (clone no 49106, R\&D Systems, Abingdon, UK), CXCL10 (clone 4D5, BD Biosciences, Stockholm, Sweden), CXCL11 (clone 87328, R\&D Systems), CCL17 (clone 54026, R\&D Systems) and CCL22 (clone 57226, R\&D Systems) antibodies were used.

2000 coupled microspheres dissolved in 50 4 PBS (Medicago AB) with 1\% bovine serum albumin (BSA, Sigma-Aldrich, Stockholm, Sweden) were added to each well of a $1.2 \mu \mathrm{m}$ pore-size filter plate (Millipore multiscreen, Millipore Corporation, Bedford, USA). Recombinant human CXCL9, CXCL10, CXCL11, CCL17 and CCL22 (R\&D Systems) were used as standards. $50 \mu \mathrm{l}$ blank and diluted samples (final dilution 1:2) were also added to the 
microspheres and incubated over night at $4^{\circ} \mathrm{C}$. After 2 washes, the microspheres were resuspended in $100 \mu \mathrm{l}$ biotinylated anti-human CXCL10 (1000 ng/ml, clone BD Biosciences, Stockholm, Sweden), CXCL9 (500 ng/ml, BAF392), CXCL11 (500 ng/ml, BAF320), CCL17 (500 ng/ml, BAF364) and CCL22 (200 ng/ml, BAF336) antibody (R\&D Systems) solution. After a 1-h incubation, the microspheres were washed twice, resuspended and incubated in $100 \mu \mathrm{l}$ of $1 \mu \mathrm{g} / \mathrm{ml}$ Streptavidin R-phycoerythrin conjugate (Molecular Probes, Eugene, USA) for 30 minutes. After 2 washes, the samples were analysed on a Luminex ${ }^{100}$ instrument (Biosource, Nivelles, Belgium) and the data were acquired using the StarStation 2.3 software (Applied cytometry systems, Sheffield, UK) with 5-parametric-curve fitting. Blank values were subtracted from all readings.

The possibility of cross-reactivity between the different microsphere sets was investigated by comparing the median fluorescence intensity (MFI) generated from a standard curve of the monoplex assay with the MFI generated from the corresponding standard curve of the pentaplex assay. This was performed for all combinations of microsphere sets and the MFI generated from the pentaplex assay was similar to those generated from the monoplex assays. The specificity of the assay was also evaluated by mixing all microsphere sets with a single chemokine standard in the middle part of the curve $(2500 \mathrm{pg} / \mathrm{ml}$ for CXCL9, $2000 \mathrm{pg} / \mathrm{ml}$ for CXCL11, $500 \mathrm{pg} / \mathrm{ml}$ for CCL17 and $1000 \mathrm{pg} / \mathrm{ml}$ for CXCL10 and CCL22). A cocktail of all biotinylated detection antibodies were added to the wells. Positive readings were achieved for the microspheres coupled with the specific capture antibody for the current chemokine, whereas irrelevant chemokines did not show any readings above background for any microsphere sets. Taken all together, no cross-reactivity between the assay components was observed in the present setting. 
The limit of detection was $14 \mathrm{pg} / \mathrm{ml}$ for CXCL9 , $6 \mathrm{pg} / \mathrm{ml}$ for CXCL10, $6 \mathrm{pg} / \mathrm{ml}$ for CXCL11, $2 \mathrm{pg} / \mathrm{ml}$ for CCL17 and $2 \mathrm{pg} / \mathrm{ml}$ for CCL22.

All samples were analysed in duplicates and the sample was re-analysed if the coefficient of variance $(\mathrm{CV})$ was $>15 \%$. In total, $6.9 \%$ of all samples were reanalyzed. The intra-assay variation was $<10 \%$, evaluated by testing one internal control sample in 12 wells at the same time point. Since samples from the study groups consisted of both plasma and serum samples, the correlation between plasma and serum samples was evaluated. Both serum and plasma samples were collected at the same time point from eleven children. Chemokine levels correlated mostly well in these samples: CXCL9 ( $p<0.001$, rho=0.90), CXCL10 ( $p=0.12$, rho=0.48), CXCL11 (p=0.03, rho=0.63) CCL17 ( $\mathrm{p}=0.02$, rho=0.68), CCL18 (p=0.01, rho=0.84), CCL22 ( $\mathrm{p}=0.048$, rho=0.58).

\section{ELISA:}

CCL18 existed in substantially higher concentration in peripheral blood than the other chemokines. Therefore, CCL18 was assessed separately with sandwich ELISA as previously described [6] using monoclonal anti-human CCL18 (clone 64507, R\&D Systems) for coating and biotinylated anti-human CCL18 antibody (BAF394, R\&D Systems) for detection. The cord blood samples were diluted 1/200 and the 6,12 and 24-month samples were diluted 1/800. The detection limit for CCL18 was $8 \mathrm{pg} / \mathrm{ml}$. All samples were analysed in duplicates and the sample was re-analysed if the $\mathrm{CV}$ was $>15 \%$.

\section{Statistical analysis}

Non-parametric tests were used, since the chemokine levels were not normally distributed. The correlations were analyzed with Spearman's rank order correlation coefficient test, comparisons between paired groups with Wilcoxon's test and unpaired groups with Mann- 
Whitney U-test. Friedman's test was employed in analyses of multiple longitudinal measures obtained from the same subject, and repeated-measures ANOVA in analyses of multiple longitudinal measures of a specific chemokine in subjects in two different groups. When a sample was missing from a subject at any age, the value corresponding to the median value for the specific chemokine at that age and group was given before repeated-measures ANOVA was performed. Because of the non-normal distribution, a log transformation was performed before ANOVA. Logistic regression and repeated-measures ANOVA were employed in adjustments for potential confounders affecting the chemokine analyses. Potential confounders were defined as factors that both significantly affected the outcome and were associated with the specific chemokine at that age. The $X^{2}$ test was used to compare the prevalence of outcome variables and background factors between the groups. A probability level of $<0.05$ was considered to be statistically significant. The calculations were made with the statistical package SPSS 16.0 for Windows (SPSS Inc, Chicago, IL, USA). 


\section{Results}

Kinetics of Th1 and Th2 chemokines

The highest Th2-associated chemokine levels were detected at birth and then decreased, whereas the Th1-associated chemokines increased with age (Table 2). The exception from this pattern was the Th2-associated chemokine CCL18, which increased with age (Table 2). Friedman's test for the whole period was significant for all chemokines $(\mathrm{p}<0.001)$ except CXCL11. The CXCL11 levels were significantly higher at 24 months than in cord blood, however (Table 2). The Th2-associated chemokines CCL17 and CCL22 correlated at every time point and so did the Th1-associated chemokines CXCL10 and CXCL11 (Supplementary Table 1). Furthermore, the Th2-associated chemokines CCL17 and CCL22 were inversely correlated with the Th1-associated chemokines CXCL10 and CXCL11.

\section{Probiotic treatment}

There was no significant difference in chemokine levels between the L. reuteri and placebo treated group. Presence of $L$. reuteri in stool the first week of life was associated with lower CCL22 and CCL17 and higher CXCL11 levels at six months of life, however [median, (interquartile range) pg/ml: 445 (332-754) vs. 830 (531-943) p=0.02, 194 (82-338) vs. 368 (235-574) $\mathrm{p}=0.006$ and 358 (129-728) vs. 115 (72-390) $\mathrm{p}=0.03 ; \mathrm{p}=0.016$ for CCL22 with repeated measures ANOVA for the samples from 6 to 24 months of age].

\section{Relationship with eczema and recurrent wheeze}

Eczema development was associated with high levels of all Th2-associated chemokines the first year of life (Table 3, $\mathrm{p}=0.004$ for CCL17, $\mathrm{p}=0.01$ for CCL18 and $\mathrm{p}=0.02$ for CCL22 with repeated-measures ANOVA). In contrast, low Th1-associated chemokines associated with eczema, although only significantly so for CXCL10 at 12 months (Table 3, p=0.09 for 
Table 2. The kinetics of circulating Th1 and Th2-associated chemokines levels [median (25-75th percentiles)] from birth until 24 months of age in 161 children regardless of treatment and presence of allergic symptoms

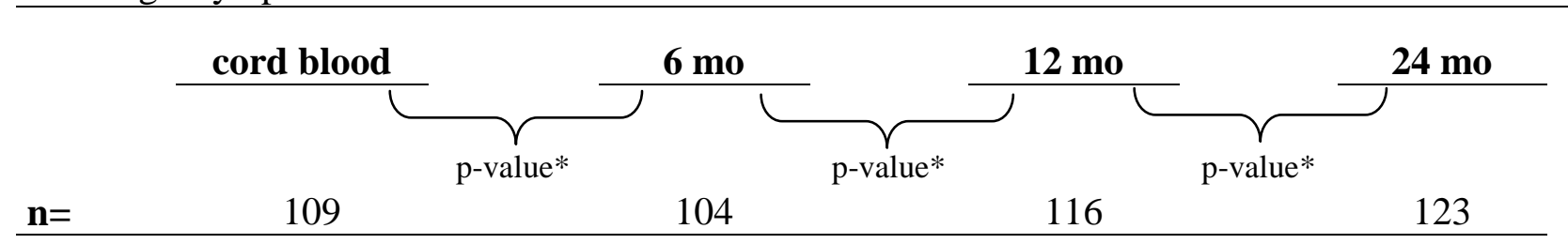

$\underline{\text { Th1- associated chemokines }}$

$\begin{array}{lccccccc}\text { CXCL9 } & \mathbf{1 0 2} & <0.001 & \mathbf{1 8 8} & 0.03 & \mathbf{2 3 3} & \text { ns } & \mathbf{2 2 2} \\ \text { pg/ml } & (79-142) & & (131-311) & & (239-321) & & (152-337) \\ \begin{array}{l}\text { CXCL10 } \\ \text { pg/ml }\end{array} & \mathbf{2 1} & <0.001 & \mathbf{5 4} & 0.02 & \mathbf{6 9} & \text { ns } & \mathbf{7 8} \\ \text { CXCL11 } & (14-32) & & (30-96) & & (45-112) & & (53-119) \\ \text { pg/ml } & \mathbf{1 9 5 * *} & \text { ns } & \mathbf{2 5 8} & \text { ns } & \mathbf{5 0 4} * * & \text { ns } & \mathbf{5 2 1} * * \\ & (137-352) & & (109-646) & & (159-668) & & (334-675)\end{array}$

Th2- associated chemokines

\begin{tabular}{lccccccc} 
CCL17 & $\mathbf{4 7 4}$ & $<0.001$ & $\mathbf{2 7 5}$ & $<0.001$ & $\mathbf{1 5 9}$ & $<0.001$ & $\mathbf{1 0 3}$ \\
$\mathbf{~ p g / m l}$ & $(270-676)$ & & $(148-503)$ & & $(54-327)$ & & $(54-209)$ \\
$\begin{array}{l}\text { CCL18 } \\
\text { ng/ml }\end{array}$ & $\mathbf{3 0}$ & $<0.001$ & $\mathbf{1 2 3}$ & 0.01 & $\mathbf{1 5 1}$ & ns & $\mathbf{1 5 7}$ \\
CCL22 & $(22-41)$ & & $(83-179)$ & & $(103-206)$ & & $(83-179)$ \\
$\mathbf{p g} / \mathbf{m l}$ & $\mathbf{6 2 2}$ & ns & $\mathbf{5 9 0}$ & $<0.001$ & $\mathbf{3 1 5}$ & $<0.001$ & $\mathbf{2 4 4}$ \\
\hline
\end{tabular}

* Wilcoxon's test for paired samples. Friedman's test was significant for all chemokines $(\mathrm{p}<0.001)$ but CXCL11 ( $\mathrm{p}=0.66)$. ${ }^{*} *$ When comparing the levels of CXCL11 in cord blood with the levels at 12 and 24 months, $\mathrm{p}=0.009$ and $\mathrm{p}=0.02$, respectively (Wilcoxon's test).

CXCL10 and $\mathrm{p}=0.03$ for CXCL11 with repeated-measures ANOVA). A Th2/Th1 ratio indicates the Th2/Th1-balance, and the CCL22/CXCL10-ratio at birth has previously been associated with subsequent allergic disease [6]. Therefore this ratio was assessed also in our study. Indeed, eczema was preceded by an elevated CCL22/CXCL10 ratio already at birth (Fig. 1a, $\mathrm{p}=0.02$ with repeated measures ANOVA).

The relationship between recurrent wheeze and chemokine levels displayed a somewhat different pattern. Although recurrent wheeze was associated with elevated levels of all Th2- 
Table 3. The levels of Th1- and Th2-associated chemokines in cord blood and in peripheral blood at 6 , 12 and 24 months in infants developing eczema and infants without any allergic manifestation until two years of age, including both probiotic and placebo treated children [median (25-75th percentiles)]

\begin{tabular}{|c|c|c|c|c|c|c|c|c|}
\hline & \multicolumn{2}{|c|}{ cord blood } & \multicolumn{2}{|c|}{6 months } & \multicolumn{2}{|c|}{12 months } & \multicolumn{2}{|c|}{24 months } \\
\hline & \multicolumn{2}{|c|}{ eczema } & \multicolumn{2}{|c|}{ eczema } & \multicolumn{2}{|c|}{ eczema } & \multicolumn{2}{|c|}{ eczema } \\
\hline & no & yes & no & yes & no & yes & no & yes \\
\hline $\mathbf{n}=$ & 51 & 35 & 53 & 30 & 53 & 42 & 55 & 43 \\
\hline \multicolumn{9}{|c|}{ Th1-associated chemokines } \\
\hline $\begin{array}{l}\text { CXCL9 } \\
\mathrm{pg} / \mathrm{ml}\end{array}$ & $\begin{array}{c}104 \\
(71-136)\end{array}$ & $\begin{array}{c}101 \\
(80-169)\end{array}$ & $\begin{array}{c}169 \\
(124-290)\end{array}$ & $\begin{array}{c}168 \\
(131-336)\end{array}$ & $\begin{array}{c}238 \\
(165-323)\end{array}$ & $\begin{array}{c}246 \\
(194-308)\end{array}$ & $\begin{array}{c}225 \\
(170-347)\end{array}$ & $\begin{array}{c}172 \\
(118-278)\end{array}$ \\
\hline $\begin{array}{l}\text { CXCL10 } \\
\mathrm{pg} / \mathrm{ml}\end{array}$ & $\begin{array}{c}21 \\
(14-35)\end{array}$ & $\begin{array}{c}19 \\
(13-29)\end{array}$ & $\begin{array}{c}54 \\
(32-98)\end{array}$ & $\begin{array}{c}46 \\
(27-68)\end{array}$ & $\begin{array}{c}81 * \\
(48-141)\end{array}$ & $\begin{array}{c}59 * \\
(43-75)\end{array}$ & $\begin{array}{c}82 \\
(54-121)\end{array}$ & $\begin{array}{c}67 \\
(49-110)\end{array}$ \\
\hline $\begin{array}{l}\text { CXCL11 } \\
\mathrm{pg} / \mathrm{ml}\end{array}$ & $\begin{array}{c}214 \\
(156-471)\end{array}$ & $\begin{array}{c}192 \\
(125-225)\end{array}$ & $\begin{array}{c}445 \\
(133-644)\end{array}$ & $\begin{array}{c}186 \\
(99-463)\end{array}$ & $\begin{array}{c}527 \\
(330-725)\end{array}$ & $\begin{array}{c}405 \\
(124-622)\end{array}$ & $\begin{array}{c}490 \\
(317-631)\end{array}$ & $\begin{array}{c}545 \\
(394-670)\end{array}$ \\
\hline
\end{tabular}

\section{$\underline{\text { Th2-associated chemokines }}$}

$\begin{array}{lcccccccc}\mathbf{C C L 1 7} & 412 & 513 & 230 * & 359 * & 129 * & 239 * & 96 & 138 \\ \mathbf{p g / m l} & (227-660) & (344-618) & (129-376) & (223-571) & (47-232) & (90-430) & (31-143) & (57-234) \\ \text { CCL18 } & 28 & 30 & 105 & 144 & 131 * & 164 * & 153 & 161 \\ \mathbf{n g} / \mathbf{m l} & (22-37) & (23-38) & (76-158) & (87-187) & (96-188) & (125-207) & (96-191) & (125-207) \\ \text { CCL22 } & 535 & 608 & 458 * & 781 * & 279 * * & 368 * * & 240 & 244 \\ \mathbf{p g / m l} & (338-789) & (410-836) & (328-732) & (433-910) & (195-350) & (270-624) & (146-304) & (138-400)\end{array}$

$* \mathrm{p}<0.05, * * \mathrm{p}<0.01$ with Mann-Whitney U-test.

associated chemokines from birth until 2 years of age (Table 4, $\mathrm{p}=0.001$ for CCL17, $\mathrm{p}<0.001$ for CCL18 and p=0.02 for CCL22 with repeated-measures ANOVA), recurrent wheeze was additionally associated with high Th1-associated chemokines at 2 years of age, significantly so for CXCL11 (Table 3) and a statistical trend for CXCL10 (p=0.07). In contrast to the other Th2-associated chemokines, CCL18 was also elevated at 6, 12 and 24 months in nonsensitized infants with recurrent wheeze ( $\mathrm{p}=0.01$ for all ages). 
(a)

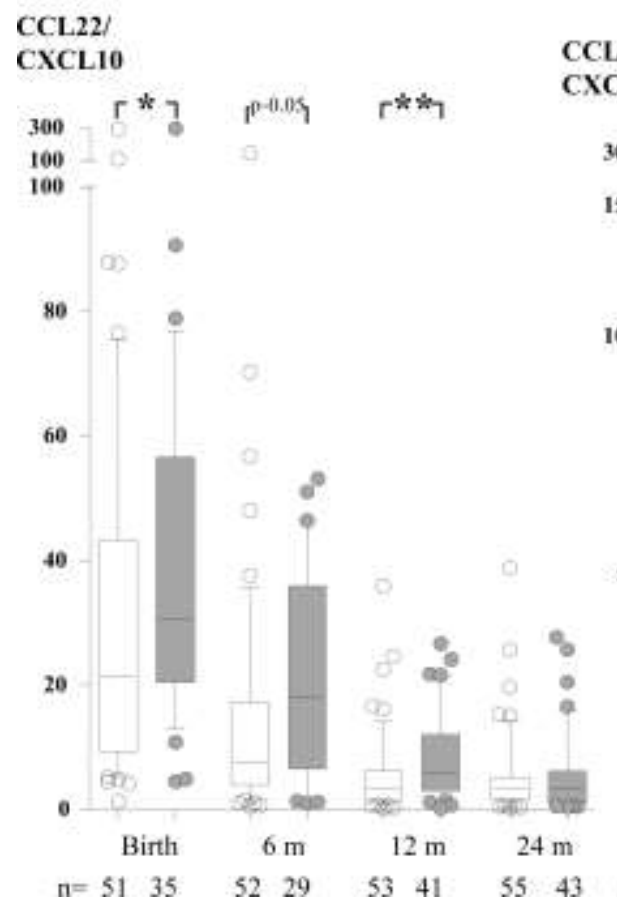

(b)

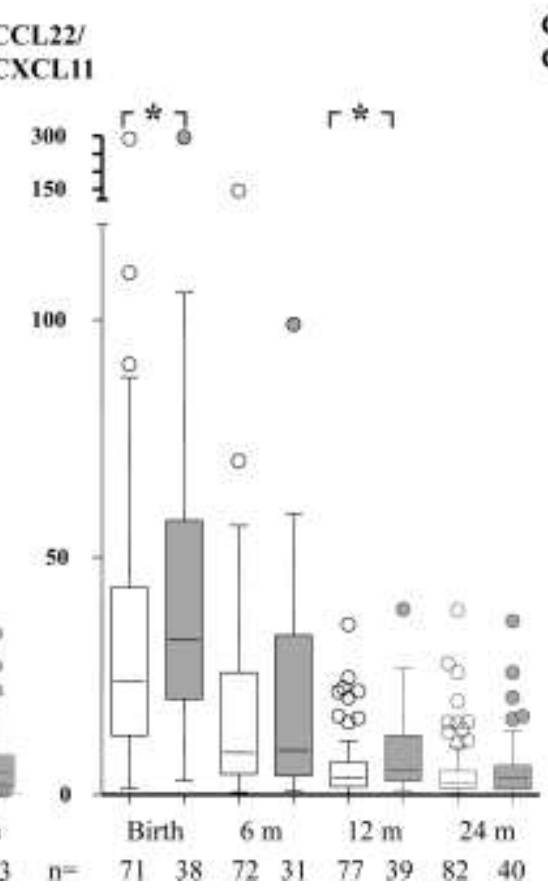

(c)

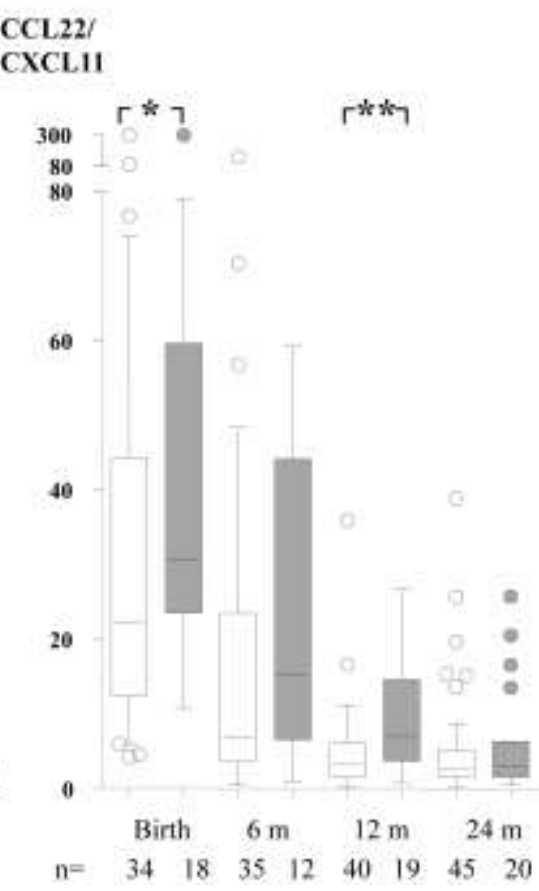

Figure 1. The CCL22/CXCL10 ratio (c) in cord blood and in peripheral blood at 6, 12 and 24 months in infants developing eczema (a), sensitization (b) and IgE-associated eczema (c) (closed bars) and infants without any allergic manifestation (open bars), including both probiotic- and placebo-treated children. The 10th, 25th, 50th, 75th and 90th percentiles are indicated. $* \mathrm{P}<0.05, * * \mathrm{P}<0.01$.

\section{Sensitization and IgE-associated allergic disease}

High CCL22 levels at birth and during the first year of life were associated with sensitization (circulating IgE to food allergens and/or positive SPT) (Fig. 2a; $p=0.03$ with repeatedmeasures ANOVA), while there was no significant association with the other chemokines (data not shown). Furthermore, SPT positive, as compared to negative, infants had low levels of the Th1-associated chemokine CXCL11 at birth and 24 months of age (Fig. 2b; 0.005 with repeated-measures ANOVA). Interestingly, none of the neonates with CXCL11 levels above the upper quartile at birth developed a positive SPT. High CCL22 levels was also associated with SPT positivity ( $\mathrm{p}=0.009$ with repeated-measures ANOVA, data not shown). 
Table 4. The levels of Th1- and Th2-associated chemokines in cord blood and in peripheral blood at 6 , 12 and 24 months in infants developing recurrent wheeze and infants without any allergic manifestation until two years of age, including both probiotic and placebo treated children [median (25-75th percentiles)]

\begin{tabular}{|c|c|c|c|}
\hline cord blood & 6 months & 12 months & 24 months \\
\hline recurrent wheeze & recurrent wheeze & recurrent wheeze & recurrent wheeze \\
\hline yes & yes & yes & yes \\
\hline 10 & 53 & 10 & 56 \\
\hline
\end{tabular}

Th1- associated chemokines

$\begin{array}{lcccccccc}\text { CXCL9 } & 104 & 120 & 169 & 289 & 238 & 301 & 225 & 223 \\ \text { pg/ml } & (71-136) & (51-159) & (124-290) & (131-384) & (165-323) & (182-477) & (170-347) & (184-472) \\ & & & & & & & & \\ \text { CXCL10 } & 21 & 16 & 54 & 67 & 83 & 59 & 82 & 114 \\ \text { pg/ml } & (14-35) & (12-24) & (32-98) & (26-86) & (48-141) & (37-105) & (54-121) & (72-210) \\ \text { CXCL11 } & 214 & 166 & 445^{*} & 109^{*} & 526 & 529 & 490^{*} & 687^{*} \\ \text { pg/ml } & (156-471) & (90-242) & (133-644) & (60-334) & (330-725) & (118-744) & (317-631) & (593-1101)\end{array}$

$\underline{\text { Th2- associated chemokines }}$

\begin{tabular}{|c|c|c|c|c|c|c|c|c|}
\hline $\begin{array}{l}\text { CCL17 } \\
\mathrm{pg} / \mathrm{ml}\end{array}$ & $\begin{array}{c}412 * \\
(227-660)\end{array}$ & $\begin{array}{c}615 * \\
(463-973)\end{array}$ & $\begin{array}{c}230 * \\
(129-376)\end{array}$ & $\begin{array}{c}402 * \\
(232-662)\end{array}$ & $\begin{array}{l}129 * * \\
(47-232)\end{array}$ & $\begin{array}{c}375 * * \\
(199-450)\end{array}$ & $\begin{array}{c}95 * \\
(31-143)\end{array}$ & $\begin{array}{c}211^{*} \\
(72-380)\end{array}$ \\
\hline $\begin{array}{l}\text { CCL18 } \\
\text { ng/ml }\end{array}$ & $\begin{array}{c}28 \\
(22-37)\end{array}$ & $\begin{array}{c}38 \\
(26-62)\end{array}$ & $\begin{array}{c}105^{*} \\
(76-158)\end{array}$ & $\begin{array}{c}172 * \\
(97-208)\end{array}$ & $\begin{array}{c}130 * * \\
(96-188)\end{array}$ & $\begin{array}{c}231 * * \\
(142-303)\end{array}$ & $\begin{array}{c}153 * \\
(96-191)\end{array}$ & $\begin{array}{c}183^{*} \\
(142-232)\end{array}$ \\
\hline $\begin{array}{l}\text { CCL22 } \\
\mathrm{pg} / \mathrm{ml}\end{array}$ & $\begin{array}{c}535 \\
(338-789)\end{array}$ & $\begin{array}{c}535 \\
(360-1104)\end{array}$ & $\begin{array}{c}458^{*} \\
(328-732)\end{array}$ & $\begin{array}{c}776^{*} \\
(559-1237)\end{array}$ & $\begin{array}{c}279 * * \\
(195-350)\end{array}$ & $\begin{array}{c}409 * * \\
(333-759)\end{array}$ & $\begin{array}{c}240 \\
(146-304)\end{array}$ & $\begin{array}{c}321 \\
(153-425)\end{array}$ \\
\hline
\end{tabular}

$* \mathrm{p}<0.05$. ** $\mathrm{p}<0.01$ with Mann-Whitney U-test. 
(a)

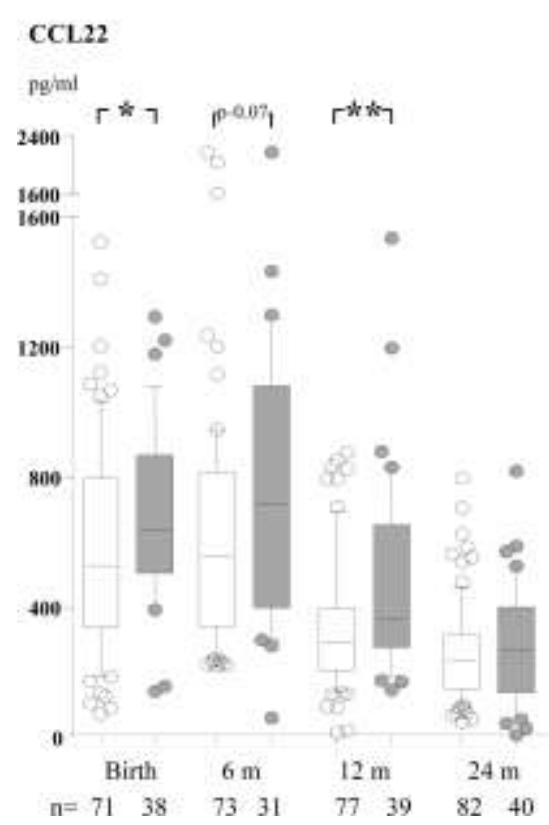

(b)

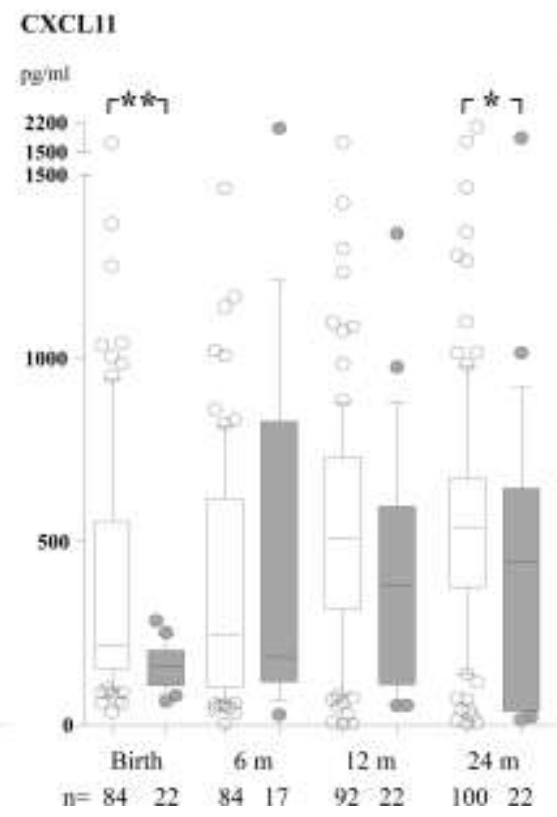

(c)

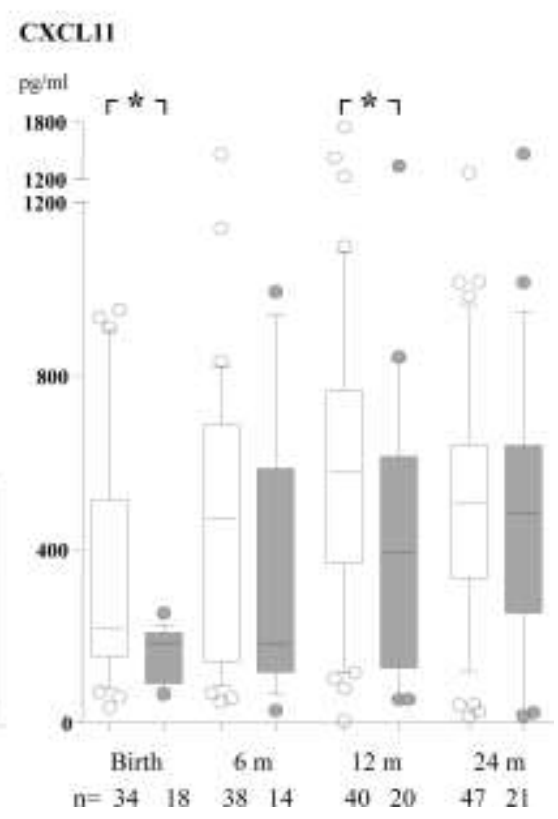

Figure 2. The levels of CCL22 (a) and CXCL11 (b and c) in peripheral blood at birth, 6, 12 and 24 months in infants with (closed bars) and without (open bars) sensitization (a), a positive skin prick test (b) or IgE-associated disease (c) until 2 years of age, including both probiotic- and placebo-treated children. $* \mathrm{P}<0.05, * * \mathrm{P}<0.01$.

The development of IgE-associated allergic disease was associated with low levels of CXCL11 ( $\mathrm{p}=0.003$ with repeated-measures ANOVA), significantly so already at birth (Fig. 2c), while CCL17 and CCL22 levels were significantly higher only at 12 months of age (data not shown, $p=0.01$ and $p=0.003$, respectively). Furthermore, eczematous infants with, as compared with without, sensitization had low CXCL11 and high CCL22 in cord blood (data not shown, $\mathrm{p}=0.02$ and $\mathrm{p}=0.03$, respectively). The Th2/Th1 ratio (CCL22/CXCL10) was also high already at birth in infants developing sensitization and IgE-associated eczema (Fig. 1b and c).

\section{Nutrition and environmental factors}

Infants who were still breastfed at 6 months had a lower incidence of SPT positivity than infants who were not $(21 \%$ vs. $38 \%, \mathrm{p}=0.049)$. Yet, breastfeeding at 6 months was related with subsequent elevated CCL22 levels ( $\mathrm{p}=0.02$ with repeated-measures ANOVA for 6, 12 
and 24 months, data not shown). Day-care attendance was associated with reduced SPT reactivity ( $20 \%$ vs. $44 \%, \mathrm{p}=0.003)$ and IgE-associated eczema ( $19 \%$ vs. $39 \%, \mathrm{p}=0.02)$, but tended to be related to an increased incidence of recurrent wheeze $(11 \%$ vs. $0 \%, p=0.05)$. Furthermore, day-care attendance the second year of life was clearly associated with elevated levels of all Th1-associated chemokines (Fig 3). Infections were more common in infants attending day-care (5.7 vs. 4.3 times, $\mathrm{p}=0.03$, t-test), but the number of infections and prescription of antibiotics did not correlate with the chemokine levels.

Adjustments with potential confounders possibly affecting the relationship between the chemokines and allergic manifestations or other factors such as treatment group, L. reuteri colonization, breastfeeding and day-care did not affect the result significantly with one exception: CXCL11 was not significantly lower at 24 months of age in SPT positive, as compared to negative infants after adjustment with day-care attendance.

(a)

CXCL9

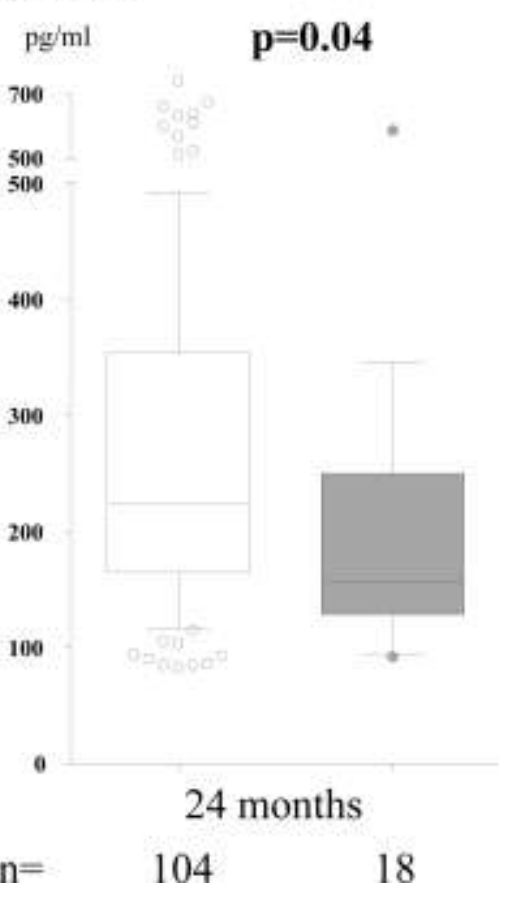

(b)

CXCL10

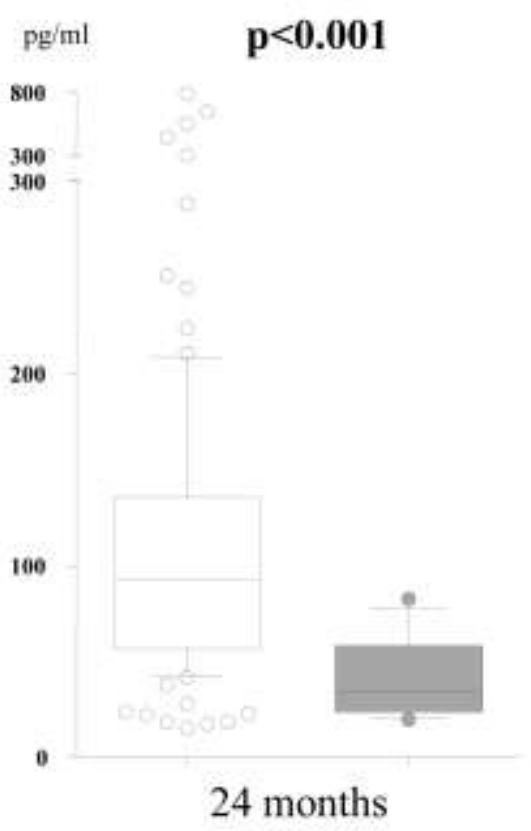

$\mathrm{n}=$

104 (c)

\section{CXCL11}
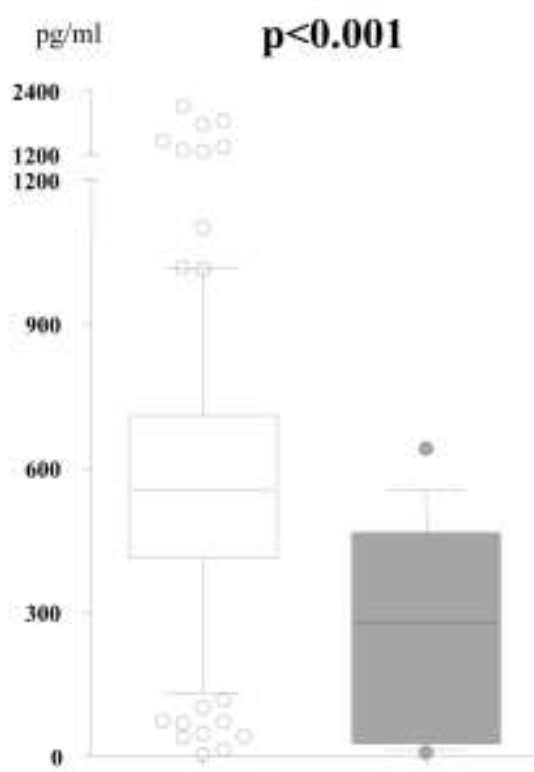

24 months

105

Figure 3. Levels of CXCL9 (a), CXCL10 (b) and CXCL11 (c) in peripheral blood at 24 months in infants attending (open bars) and not attending (closed bars) day-care the second year of life. The 10th, 25th, 50th, 75th and 90th percentiles as well as outliers are indicated. 


\section{Discussion}

This prospective study revealed that an imbalance in circulating Th1- and Th2-associated chemokines may precede the onset of sensitization, eczema and recurrent wheeze from birth, implicating that these chemokines may sometimes be primarily involved in the pathogenesis of allergic diseases and not only secondary to a general immune deviation after disease onset. Th1 and Th2 cytokines are likely important upstream mediators of these effects, as they induce production of the respective chemokines. The subsequent delay in maturation of the immune system with a prolonged Th2-deviation in children developing allergic disease supports and extends previous reports [2,3]. Our findings extend previous reports of elevated levels of Th2-associated chemokines in patients with eczema and recurrent wheeze $[8,9,12$, $13,20]$ showing that elevated levels also precede clinical manifestations. Determination of circulating chemokine levels in epidemiological studies may be a tool for identification of factors associated with the development of sensitization or allergic disease.

Eczema did not associate significantly with any chemokine the second year of life, whereas recurrent wheeze was significantly associated with high CCL17 and CCL18 also at 24 months. Moreover, in contrast to eczema and sensitization, recurrent wheeze was related to elevated Th1-associated chemokines the second year of life, which is in concordance with previous reports. Elevated CXCL10 levels have been reported in BAL from asthmatic patients after allergen exposure [21]. Although CXCL10 favored Th1-like response in lymph nodes in a mouse model, it attracted Th2-cells and eosinophils locally in lung at a late stage of airway inflammation [22]. Thus, when the subject once has become asthmatic, Th1-inducing factors might aggravate the asthmatic inflammation $[22,23]$. 
It has been suggested that CCL18, previously named pulmonary- and activation-regulated chemokine, has a key role in asthma [13], and it was strongly associated with recurrent wheeze in our material. It is preferentially expressed in the lung by antigen presenting cells and is induced by Th2-associated chemokines [13]. It is not strictly a Th2-associated chemokine, however, since its receptor is still not known, and its expression seems to be differently regulated than CCL17 and CCL22. Thus, while IL-4 and IL-13 induce CCL17, CCL22 and CCL18, the anti-inflammatory cytokine IL-10 enhances CCL18 expression and reduces CCL17 and CCL22 secretion [24-26]. In contrast to the other Th2-associated chemokines, the CCL18 levels increased during infancy in our study and were also associated to non-sensitized recurrent wheeze.

The Th2-associated chemokine CCL17 was elevated already at birth in infants who subsequently developed recurrent wheeze. Recently, it was suggested that DCs are the primary source of CCL17 and CCL22 in the lung, and that CCL17 and CCL22 are critical for the recruitment of Th2 cells into the airways during allergic inflammation [27]. Furthermore, the CCR4 receptor is required for efficient entry of both iNKT [28] and antigen-specific Th2 cells [29] into the lung in murine models of pulmonary allergic inflammation. Thus, infants developing recurrent wheeze may be predisposed for pulmonary allergic inflammation already from birth.

Interestingly, only two of the chemokines were related to sensitization, CCL22 and CXCL11. Although CCL22 share the same Th2-associated receptor, CCR4, with CCL17, there are differences in the regulation of the expression of these chemokines. While CCL22 is not produced by endothelium, CCL17 is expressed on dermal vascular endothelial cells in inflamed skin [30, 31]. Circulating CCL17 levels may therefore relate more strongly to skin 
symptoms, which was supported by our result. In contrast, as dendritic cells produce higher levels of CCL22 than CCL17 [32], particularly after CD40L ligation [33], it is tempting to speculate that CCL22 may be involved in the allergen sensitization process. Also, we hypothesize that the higher CXCR3 affinity and potency of CXCL11 compared with CXCL9 and CXCL10 [34] may possibly explain why reduced neonatal levels of this chemokine were related to sensitization. The fact, that subsequent sensitization was related to reduced CXCL11 and elevated CCL22 levels in cord blood, reflecting the in utero condition, supports the theory that sensitization might be associated with immune programming during the fetal period $[35,36]$.

Although the presence of $L$. reuteri in infant stool the first week of life was associated with low CCL17 and CCL22 and high CXCL11 levels at 6 months, no differences in chemokine levels were revealed between the L. reuteri and placebo treated group. Therefore thepreviously reported effect on IgE-associated eczema by L. reuteri [17] seems to be primarily mediated by another mechanism. Lactobacillus reuteri has been associated with induction of anti-inflammatory cytokines and T regulatory cells in human in vitro and animal models [37] [38].

This study confirms that humans are born Th2-skewed, as found in most [39-41] but not all [42] studies, and gradually develop a Th1/Th2-balance. This process is stimulated by environmental factors, such as exposure to commensal microflora [43]. Attendance to daycare was the most Th1-stimulating factor in this study. Accordingly, this was also related to a lower incidence of sensitization and IgE-associated eczema, which is consistent with previous reports [44]. The lack of correlation between infection rate and the Th1-associated chemokines suggests that the effect of day-care most likely is mediated by enhanced exposure 
to commensal microbiotia [45]. Besides day-care attendance, CXCL9 was not associated with any other variable in our study. Thus, CXCL9 may not be interesting in in vivo studies such as this one, speculatively due to its having the lowest CXCR3-affinity of the Th1-associated chemokines [34]. Only infants with a family history of allergic disease were included in the original study, which might have influenced some results, but probably not the significant differences between infants developing allergic disease or not. In an independent cohort where children both with and without allergic heredity were included, elevated cord blood CCL22 levels preceded development of sensitisation and elevated CCL17 levels were associated with development of allergic symptoms, further supporting our findings [6].

In conclusion, the Th2-associated chemokines CCL17 and CCL22 were as highest at birth and then decreased, whereas CCL18 and the Th1-associated chemokines CXCL10 and CXCL 11 increased with age. Allergic disease in infancy was associated with low circulating Th1and high Th2-associated chemokine levels in infancy. Sensitization was preceded by low levels of CXCL11 and high levels of CCL22 already at birth. Of clinical relevance, circulating chemokines are useful for investigating the Th1/Th2 imbalance in allergic disease in vivo. Elucidation of the role of chemokines in allergic diseases may lead to future treatments.

\section{Ackowledgements}

We thank Mrs Lena Lindell, Mrs Elisabeth Andersson, Mrs Linnea Andersson and Mrs Eivor Folkesson, Dr Göran Oldaeus and Dr Ted Jacobsson for their brilliant and enthusiastic work guiding the families through the study and all the sampling procedures. We also thank Mrs Anne-Marie Fornander for excellent technical assistance and Mats Fredrikson, Division of 
Occupational and Environmental Medicine, Linköping University, for valuable help with the statistical analyses.

The study was supported by grants from BioGaia AB, Stockholm, Sweden, the Ekhaga

Foundation, the Heart and Lung foundation, the Research Council for the South-East Sweden (grant No. F2000-106), the Swedish Asthma and Allergy Association, the Swedish Research Council and the University Hospital of Linköping, Sweden. T Abrahamsson and M Jenmalm and B Björkstén have received honaria for lectures from Biogaia AB.

\section{References}

1. Kondo N, Kobayashi Y, Shinoda S, Takenaka R, Teramoto T, Kaneko H, Fukao T, Matsui E, Kasahara K, Yokoyama Y, Reduced interferon gamma production by antigen-stimulated cord blood mononuclear cells is a risk factor of allergic disorders-6-year follow-up study. Clin Exp Allergy 1998;28: 1340-1344.

2. Böttcher MF, Björkstén B, Jenmalm MC, Immune response to birch in young children during their first 7 years of life. Clinical and Experimental Allergy 2002;32: 16901698.

3. Prescott SL, Macaubas C, Smallacombe T, Holt BJ, Sly PD, Holt PG, Development of allergen-specific T-cell memory in atopic and normal children. Lancet 1999;353: 196200.

4. Yazdanbakhsh M, Kremsner PG, van Ree R, Allergy, parasites, and the hygiene hypothesis. Science 2002;296: 490-494.

5. Stene LC, Nafstad P, Relation between occurrence of type 1 diabetes and asthma. Lancet 2001;357: 607-608.

6. Sandberg M, Frykman A, Ernerudh J, Berg G, Matthiesen L, Ekerfelt C, Nilsson LJ, Jenmalm MC, Cord blood cytokines and chemokines and development of allergic disease. Pediatr Allergy Immunol 2009;20: 519-527.

7. Pease JE, Williams TJ, Chemokines and their receptors in allergic disease. J Allergy Clin Immunol 2006;118: 305-318; quiz 319-320.

8. Fujisawa T, Fujisawa R, Kato Y, Nakayama T, Morita A, Katsumata H, Nishimori H, Iguchi K, Kamiya H, Gray PW, Chantry D, Suzuki R, Yoshie O, Presence of high contents of thymus and activation-regulated chemokine in platelets and elevated plasma levels of thymus and activation-regulated chemokine and macrophage-derived chemokine in patients with atopic dermatitis. J Allergy Clin Immunol 2002;110: 139146.

9. Jahnz-Rozyk K, Targowski T, Paluchowska E, Owczarek W, Kucharczyk A, Serum thymus and activation-regulated chemokine, macrophage-derived chemokine and eotaxin as markers of severity of atopic dermatitis. Allergy 2005;60: 685-688.

10. Kakinuma T, Nakamura K, Wakugawa M, Mitsui H, Tada Y, Saeki H, Torii H, Komine M, Asahina A, Tamaki K, Serum macrophage-derived chemokine (MDC) 
levels are closely related with the disease activity of atopic dermatitis. Clin Exp Immunol 2002;127: 270-273.

11. Gunther C, Bello-Fernandez C, Kopp T, Kund J, Carballido-Perrig N, Hinteregger S, Fassl S, Schwarzler C, Lametschwandtner G, Stingl G, Biedermann T, Carballido JM, CCL18 is expressed in atopic dermatitis and mediates skin homing of human memory T cells. J Immunol 2005;174: 1723-1728.

12. Hartl D, Griese M, Nicolai T, Zissel G, Prell C, Konstantopoulos N, Gruber R, Reinhardt D, Schendel DJ, Krauss-Etschmann S, Pulmonary chemokines and their receptors differentiate children with asthma and chronic cough. J Allergy Clin Immunol 2005;115: 728-736.

13. de Nadai P, Charbonnier AS, Chenivesse C, Senechal S, Fournier C, Gilet J, Vorng H, Chang Y, Gosset P, Wallaert B, Tonnel AB, Lassalle P, Tsicopoulos A, Involvement of CCL18 in allergic asthma. J Immunol 2006;176: 6286-6293.

14. Pilette C, Francis JN, Till SJ, Durham SR, CCR4 ligands are up-regulated in the airways of atopic asthmatics after segmental allergen challenge. Eur Respir J 2004;23: 876-884.

15. Miotto D, Christodoulopoulos P, Olivenstein R, Taha R, Cameron L, Tsicopoulos A, Tonnel AB, Fahy O, Lafitte JJ, Luster AD, Wallaert B, Mapp CE, Hamid Q, Expression of IFN-gamma-inducible protein; monocyte chemotactic proteins 1, 3, and 4; and eotaxin in TH1- and TH2-mediated lung diseases. J Allergy Clin Immunol 2001;107: 664-670.

16. Singh UP, Singh S, Iqbal N, Weaver CT, McGhee JR, Lillard JW, Jr., IFN-gammainducible chemokines enhance adaptive immunity and colitis. J Interferon Cytokine Res 2003;23: 591-600.

17. Abrahamsson TR, Jakobsson T, Böttcher MF, Fredrikson M, Jenmalm MC, Björkstén B, Oldaeus G, Probiotics in prevention of IgE-associated eczema: a double blind randomised placebo-controlled trial. Journal of Allergy and Clinical Immunology 2007;119: 1174-1180.

18. Abrahamsson TR, Sinkiewicz G, Jakobsson T, Fredrikson M, Bjorksten B, Probiotic lactobacilli in breast milk and infant stool in relation to oral intake during the first year of life. J Pediatr Gastroenterol Nutr 2009;49: 349-354.

19. de Jager W, Prakken BJ, Bijlsma JW, Kuis W, Rijkers GT, Improved multiplex immunoassay performance in human plasma and synovial fluid following removal of interfering heterophilic antibodies. J Immunol Methods 2005;300: 124-135.

20. Kakinuma T, Nakamura K, Wakugawa M, Mitsui H, Tada Y, Saeki H, Torii H, Asahina A, Onai N, Matsushima K, Tamaki K, Thymus and activation-regulated chemokine in atopic dermatitis: Serum thymus and activation-regulated chemokine level is closely related with disease activity. J Allergy Clin Immunol 2001;107: 535541.

21. Bochner BS, Hudson SA, Xiao HQ, Liu MC, Release of both CCR4-active and CXCR3-active chemokines during human allergic pulmonary late-phase reactions. J Allergy Clin Immunol 2003;112: 930-934.

22. Thomas MS, Kunkel SL, Lukacs NW, Differential role of IFN-gamma-inducible protein $10 \mathrm{kDa}$ in a cockroach antigen-induced model of allergic airway hyperreactivity: systemic versus local effects. J Immunol 2002;169: 7045-7053.

23. Tavernier G, Fletcher G, Gee I, Watson A, Blacklock G, Francis H, Fletcher A, Frank T, Frank P, Pickering CA, Niven R, IPEADAM study: indoor endotoxin exposure, family status, and some housing characteristics in English children. J Allergy Clin Immunol 2006;117: 656-662. 
24. Andrew DP, Chang MS, McNinch J, Wathen ST, Rihanek M, Tseng J, Spellberg JP, Elias CG, 3rd, STCP-1 (MDC) CC chemokine acts specifically on chronically activated Th2 lymphocytes and is produced by monocytes on stimulation with Th2 cytokines IL-4 and IL-13. J Immunol 1998;161: 5027-5038.

25. Vulcano M, Struyf S, Scapini P, Cassatella M, Bernasconi S, Bonecchi R, Calleri A, Penna G, Adorini L, Luini W, Mantovani A, Van Damme J, Sozzani S, Unique regulation of CCL18 production by maturing dendritic cells. J Immunol 2003;170: 3843-3849.

26. Tiemessen MM, Jagger AL, Evans HG, van Herwijnen MJ, John S, Taams LS, CD4+CD25+Foxp3+ regulatory $\mathrm{T}$ cells induce alternative activation of human monocytes/macrophages. Proc Natl Acad Sci U S A 2007;104: 19446-19451.

27. Medoff BD, Seung E, Hong S, Thomas SY, Sandall BP, Duffield JS, Kuperman DA, Erle DJ, Luster AD, CD11b+ myeloid cells are the key mediators of Th2 cell homing into the airway in allergic inflammation. J Immunol 2009;182: 623-635.

28. Meyer EH, Wurbel MA, Staton TL, Pichavant M, Kan MJ, Savage PB, DeKruyff RH, Butcher EC, Campbell JJ, Umetsu DT, iNKT cells require CCR4 to localize to the airways and to induce airway hyperreactivity. J Immunol 2007;179: 4661-4671.

29. Mikhak Z, Fukui M, Farsidjani A, Medoff BD, Tager AM, Luster AD, Contribution of CCR4 and CCR8 to antigen-specific $\mathrm{T}(\mathrm{H}) 2$ cell trafficking in allergic pulmonary inflammation. J Allergy Clin Immunol 2009;123: 67-73 e63.

30. Campbell JJ, Haraldsen G, Pan J, Rottman J, Qin S, Ponath P, Andrew DP, Warnke R, Ruffing N, Kassam N, Wu L, Butcher EC, The chemokine receptor CCR4 in vascular recognition by cutaneous but not intestinal memory T cells. Nature 1999;400: 776780.

31. D'Ambrosio D, Albanesi C, Lang R, Girolomoni G, Sinigaglia F, Laudanna C, Quantitative differences in chemokine receptor engagement generate diversity in integrin-dependent lymphocyte adhesion. J Immunol 2002;169: 2303-2312.

32. Penna G, Vulcano M, Roncari A, Facchetti F, Sozzani S, Adorini L, Cutting edge: differential chemokine production by myeloid and plasmacytoid dendritic cells. J Immunol 2002;169: 6673-6676.

33. Megiovanni AM, Sanchez F, Gluckman JC, Rosenzwajg M, Double-stranded RNA stimulation or CD40 ligation of monocyte-derived dendritic cells as models to study their activation and maturation process. Eur Cytokine Netw 2004;15: 126-134.

34. Cole KE, Strick CA, Paradis TJ, Ogborne KT, Loetscher M, Gladue RP, Lin W, Boyd JG, Moser B, Wood DE, Sahagan BG, Neote K, Interferon-inducible T cell alpha chemoattractant (I-TAC): a novel non-ELR CXC chemokine with potent activity on activated $\mathrm{T}$ cells through selective high affinity binding to CXCR3. J Exp Med 1998;187: 2009-2021.

35. Polte T, Hennig C, Hansen G, Allergy prevention starts before conception: maternofetal transfer of tolerance protects against the development of asthma. J Allergy Clin Immunol 2008;122: 1022-1030 e1025.

36. Mold JE, Michaelsson J, Burt TD, Muench MO, Beckerman KP, Busch MP, Lee TH, Nixon DF, McCune JM, Maternal alloantigens promote the development of tolerogenic fetal regulatory T cells in utero. Science 2008;322: 1562-1565.

37. Smits HH, Engering A, van der Kleij D, de Jong EC, Schipper K, van Capel TM, Zaat BA, Yazdanbakhsh M, Wierenga EA, van Kooyk Y, Kapsenberg ML, Selective probiotic bacteria induce IL-10-producing regulatory $\mathrm{T}$ cells in vitro by modulating dendritic cell function through dendritic cell-specific intercellular adhesion molecule 3-grabbing nonintegrin. J Allergy Clin Immunol 2005;115: 1260-1267. 
38. Karimi K, Inman MD, Bienenstock J, Forsythe P, Lactobacillus reuteri-induced regulatory $\mathrm{T}$ cells protect against an allergic airway response in mice. Am J Respir Crit Care Med 2009;179: 186-193.

39. Saito S, Nakashima A, Shima T, Ito M, Th1/Th2/Th17 and regulatory T-cell paradigm in pregnancy. Am J Reprod Immunol 2010;63: 601-610.

40. Prescott SL, Macaubas C, Holt BJ, Smallacombe TB, Loh R, Sly PD, Holt PG, Transplacental priming of the human immune system to environmental allergens: universal skewing of initial $\mathrm{T}$ cell responses toward the Th2 cytokine profile. $\mathrm{J}$ Immunol 1998;160: 4730-4737.

41. PrabhuDas M, Adkins B, Gans H, King C, Levy O, Ramilo O, Siegrist CA, Challenges in infant immunity: implications for responses to infection and vaccines. Nat Immunol;12: 189-194.

42. Halonen M, Lohman IC, Stern DA, Spangenberg A, Anderson D, Mobley S, Ciano K, Peck M, Wright AL, Th1/Th2 patterns and balance in cytokine production in the parents and infants of a large birth cohort. J Immunol 2009;182: 3285-3293.

43. Romagnani S, Coming back to a missing immune deviation as the main explanatory mechanism for the hygiene hypothesis. J Allergy Clin Immunol 2007;119: 1511-1513.

44. Krämer J, Heinrich J, Wjst M, Wichmann HE, Age of entry to day nursery and allergy in later childhood. The Lancet 1998;353: 450-452.

45. Dwinell MB, Lugering N, Eckmann L, Kagnoff MF, Regulated production of interferon-inducible T-cell chemoattractants by human intestinal epithelial cells. Gastroenterology 2001;120: 49-59. 
Supplementary Table 1. Correlation between the chemokines in cord blood and peripheral blood at 6,12 and 24 months of age.

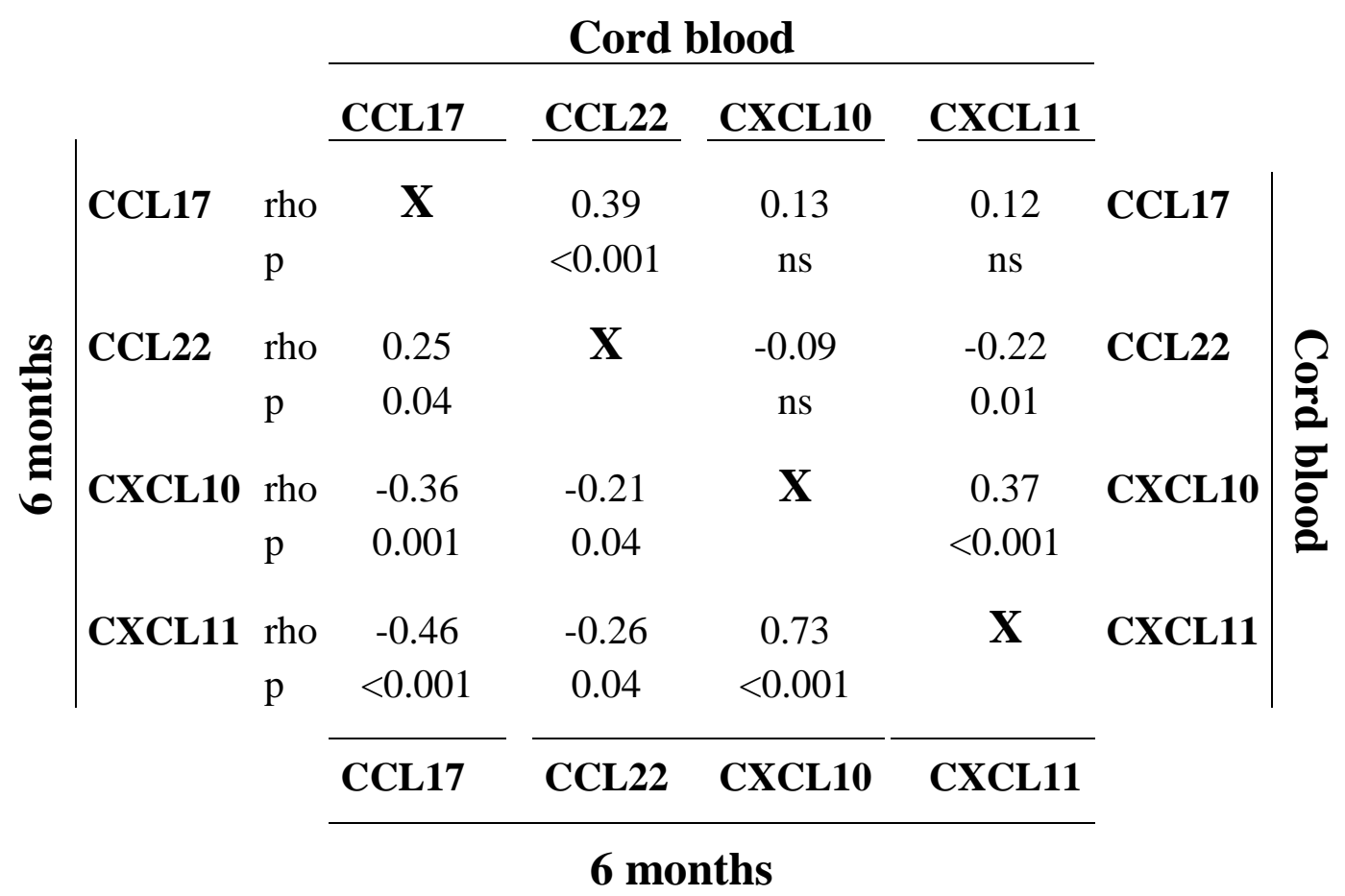

12 months

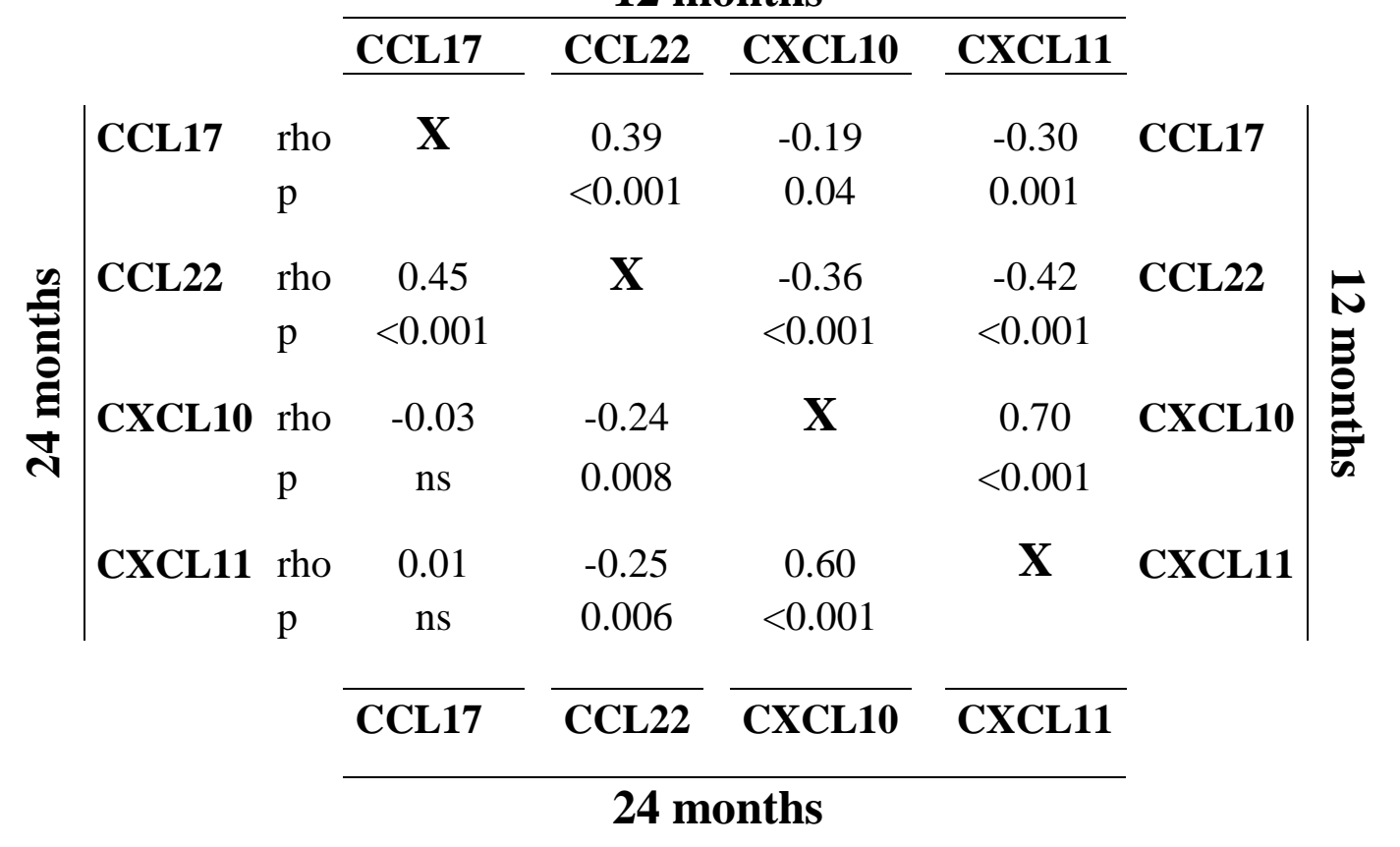

